\title{
Nelson González, Ricardo Uribe y Diana Bonnet (eds.). Comunicación, objetos y mercancías en el Nuevo Reino de Granada. Estudios de producción y circulación. Bogotá, Universidad de los Andes, 2017.
}

\author{
James Vladimir Torres Moreno*
}

7 de junio de 2018

\begin{abstract}
$\mathrm{D}$ Esde hace varios años, el grupo de historia colonial de la Universidad de los Andes (Bogotá) ha publicado sólidos análisis de la sociedad colonial del Nuevo Reino de Granada. En esta oportunidad, los autores buscan ofrecer una visión del Reino mucho más integrada al sistema colonial que la sostenida hasta el momento. Se trata de un valioso grupo de estudios que abordan un conjunto heterogéneo de mercancías que circularon a lo largo del virreinato en diferentes periodos. Un análisis de las bondades y debilidades del texto constituye, entonces, una suerte de laboratorio para entender cómo el campo de historia colonial ha evolucionado en Colombia. Naturalmente, como suele ocurrir en las compilaciones de este tipo, existen capítulos más sólidos e integrados que otros al objetivo general del texto. Sin embargo, en la presente reseña mostraré que existen ciertos rasgos que los diversos autores comparten en su abordaje de la sociedad colonial.

Los capítulos buscan entender la manera en que se introdujeron nuevas técnicas para extraer y transformar recursos al tiempo que se establecieron rutas de circulación de mercancía e información. Se trata de un valioso aporte a la historia colonial. Los compiladores, sin embargo, señalan en la introducción que "el campo de la historia de los objetos y mercancías en el mundo colonial podría calificarse como incipiente en la historiografía colombiana” (p. 3). Esta aseveración es incorrecta. La historia económica colonial reciente ha presentado importantes avances en muchos de los aspectos que aborda el libro. Con dicha literatura se puede estar de acuerdo o no. Sin embargo, una lectura atenta
\end{abstract}

\footnotetext{
${ }^{*}$ Georgetown University, Estados Unidos. Email: jvt7@georgetown.edu
} 
de dichos trabajos no sólo les hubiese permitido potenciar los casos abordados, sino también entender de manera rigurosa las lógicas de diversos aspectos de la economía colonial. A lo largo de esta reseña explicaré cómo los diversos autores pasaron por alto estudios claves de historia económica y fiscal publicados en la última década.

Permítaseme proporcionar un ejemplo de este encuadre que los compiladores anotan en la introducción. En su discusión sobre la circulación internacional de metales preciosos y mercancías, los compiladores resaltan los análisis de Earl Hamilton y Pierre Chaunu. Se trata, en efecto, de dos referencias obligadas sobre el tema. Sin embargo, los compiladores no señalan los estudios más recientes de Michel Morineau y John Tepaske que modificaron sustancialmente los hallazgos de historiadores anteriores. ${ }^{1}$ En otras palabras, algunos de los capítulos de Comunicación, objetos y mercancías adolecen de una palpable desactualización historiográfica.

El primer capítulo, escrito por Nelson González, estudia la circulación de correspondencia en el Nuevo Reino antes de la implantación gradual de las rentas de correos en 1764. Se trata de un estudio fundamental de un tema poco estudiado. El autor muestra cómo a pesar de que nunca se desplegó un sistema de correos mayores como en otros lugares del sistema colonial, la cooperación entre oficiales reales y conductores particulares permitió la circulación de correspondencia a través del virreinato. Allí radica, según González, la fortale$z a$ del sistema neogranadino. Sin embargo, el autor no ofrece una explicación sistemática de por qué el sistema de correos se transformó tardíamente en el Reino. ¿Se debe, simplemente, a la condición periférica del Nuevo Reino como el autor llega a sugerir? El texto sugiere que un gradual incremento en la rentabilidad de los correos posterior a la creación del virreinato hizo atractiva su transformación. El autor cita un ingreso neto por concepto de correos entre 1751 y 1757 para diversas cajas del virreinato como prueba del aumento de rentabilidad. Ahora bien, dicha cifra está lejos de ser un ingreso neto. Se trata, en cambio, de un by-product del trabajo de los oficiales reales quienes colocaban capacidad instalada y trabajo de otros ramos para facilitar la circulación de correspondencia. En otras palabras, sin un análisis cuidadoso de la estructura de costos reales, es imposible saber si el tema fue de rentabilidad o no.

Una apreciación de la estructura política y económica de mediados de siglo hubiese ayudado a poner en perspectiva el análisis. Tres variables deben tenerse en cuenta. Primero, los ciclos de la economía colonial que recientemente han sido estudiados. Es claro que la primera mitad de siglo fue un periodo

\footnotetext{
${ }^{1}$ M. Morineau (1985). Incroyables gazettes et fabuleux métaux. Les retours des trésors américains d'après les gazettes hollandaises (ХVIe-XVHIe siècles). Londres y París: Cambridge University Press/Éditions de la Maison des Sciences de l'Homme; J. Tepaske (2010). A New World of Gold and Silver. London: Brill.
} 
de expansión económica y que las reformas de mediados de siglo se dieron en el marco de una contracción fiscal y monetaria. ${ }^{2}$ Segundo, la activación de la política de navíos de registro tuvo implicaciones profundas sobre la capacidad de importación del Reino. En efecto, los precios de las importaciones se desplomaron y la rotación de los inventarios aumentó. ${ }^{3}$ Tercero, la descentralización monetaria del Reino con la creación de la Casa de Moneda de Popayán y el despliegue de nuevas casas de fundición alteraron la dirección y magnitud del flujo de mercancías. ${ }^{4}$ Las tres variables debieron crear un nicho perfecto para ganar economías de escala en la reorganización de los correos. Esto, naturalmente, es una hipótesis. Sin embargo, no se analizan estas estructuras que ciertamente afectaron la mecánica institucional del virreinato en dichos años.

Los dos capítulos siguientes escritos por Ricardo Uribe y Mauricio Gómez analizan, respectivamente, la circulación de relojes y vestidos en el Nuevo Reino. Se trata, de nuevo, de dos estudios novedosos sobre temas poco estudiados en la historiografía local. Uribe explora cómo la introducción y el uso de relojes no sólo es un reflejo de los cambios en la cultura material de la sociedad colonial, sino también de transformaciones de la identidad temporal de la misma. La adopción de unidades de tiempo como los segundos y los minutos constituyó, en efecto, un cambio esencial en la mentalidad de los habitantes del Reino si bien su efecto fue lento y gradual. El texto abunda en sagaces y sólidas reflexiones y sólo observaría que el argumento se hubiese fortalecido al colocar la circulación de los relojes en un diálogo más fluido con el aumento de otras importaciones a fines de siglo como lo ha analizado Nathalie Moreno. ${ }^{5}$

Gómez, por su parte, utiliza los vestidos como plataforma para estudiar diversos aspectos de la cultura material y la fluidez de las identidades étnicas en el Reino durante los siglos xvi y xviI. Su uso extensivo de casos criminales le lleva a proponer varios argumentos de los cuales resalta dos. Primero, el autor confirma en extenso que el vestuario tenía una función diferenciadora dentro de la sociedad colonial además de separar etnias, géneros y edades. Se-

\footnotetext{
${ }^{2}$ Véanse J. Torres (2013). Minería y moneda en el Nuevo Reino de Granada. El desempeño económico en la segunda mitad del siglo XVIII. Bogotá: Instituto Colombiano de Antropología e Historia; J. Torres (2015). El movimiento de los precios en una economía preindustrial. Popayán, virreinato de la Nueva Granada 1706-1819. Cuadernos de Economía, 34, 629-680.

${ }^{3} \mathrm{~J}$. Torres (2015). El movimiento de los precios en una economía preindustrial. Popayán, virreinato de la Nueva Granada 1706-1819. Cuadernos de economía, 34, 629-680.

${ }^{4}$ J. Torres (2014) Monedas de antiguo y nuevo cuño: envilecimiento y reacuñación en el Nuevo Reino de Granada en la segunda mitad del siglo xviII. Memoria y Sociedad, 18(34), 119-132; J, Torres (2013). Sencillos y piezas de a ocho. El problema de la moneda de baja denominación en el Nuevo Reino de Granada en la segunda mitad del siglo XviII. Anuario Colombiano de Historia Social y de la Cultura, 40(1), 179-212.

${ }^{5}$ N. Moreno (2013). Circulación de efectos de Castilla en el Virreinato de la Nueva Granada a finales del siglo xviII. Fronteras de la Historia, 18(1), 211-249.
} 
gundo, la existencia en el Reino de un activo mercado de ropa usada muestra la importancia y relevancia de la producción textil en esta temprana etapa de la economía colonial. Adicionalmente, sus casos permiten ver cómo Bogotá ya se configuraba como un nodo fundamental del comercio textil a escala virreinal, función que se decantará a fines de siglo XviII cuando sus mercaderes trataban en lienzos, mantas de caja y otros productos textiles a lo largo del virreinato. ${ }^{6}$

En "Palo de Brasil, contrabando y resistencia guajira en la provincia colonial de Santa Marta", Camilo Torres propone que el comercio de palo de Brasil y de otras mercancías que los guajiros mantuvieron con los ingleses y holandeses les ayudó a conservar su autonomía frente al sistema colonial español. En estas condiciones, la extirpación del comercio ilegal fue una de las razones detrás, no sólo de la ofensiva militar, sino de los diversos intentos por estancar el comercio de palo de tinte durante el siglo xviII. Así, Torres refuerza el argumento ya esgrimido por varios historiadores. Sin embargo, el autor reproduce la idea de Santa Marta como una provincia con potencial pero poco poblada y poco conectada a los circuitos comerciales formales del virreinato. Hugues Sánchez ha mostrado, sin embargo, que este argumento debe matizarse. ${ }^{7}$ En efecto, el sector rural de la gobernación estuvo constituido por una tupida red de pequeños propietarios favorecidos entre otros aspectos por la expansión de mercados regionales y por los cambios institucionales desplegados por los borbones en materia de tenencia de la tierra. Esto, por transitividad, lleva a un segundo punto. Gómez analiza el tamaño del sector exportador en términos relativos. Es decir, como porcentaje de las exportaciones agregadas del Nuevo Reino. Este ejercicio, sin embargo, oculta el peso del sector a nivel regional. El autor no analiza los eslabonamientos hacia adelante y hacia atrás del palo de Brasil que posiblemente vinculaban de manera más amplia a la expansión del palo de tinte con esa tupida red de pequeños campesinos identificados por Sánchez.

Finalmente, es importante insistir que el uso de la información de la Real Hacienda debe hacerse con tiento. El autor no explicita qué rubros y qué libros de la Real Hacienda utilizó para sostener la marginalidad del palo de tinte frente a otras fuentes de recaudo. Esto, por ejemplo, conduce al autor

\footnotetext{
${ }^{6}$ E. Muñoz y J. Torres (2013). La función de Santafé en los sistemas de intercambio de la Nueva Granada a fines del siglo XviII. Fronteras de la Historia, 18(1), 165-211.

${ }^{7}$ H. Sánchez (2011). De esclavos a campesinos, de la "roza” al mercado: tierra y producción agropecuaria de los "libres de todos los colores" en la gobernación de Santa Marta (1740-1810). Historia Crítica, 43, 130-155; H. Sánchez (2012). Composición, mercedes de tierras realengas y expansión ganadera en una zona de frontera de la gobernación de Santa Marta; Valledupar (1700-1810). Anuario Colombiano de Historia Social y de la Cultura, 39(1), 81-117; H. Sánchez (2016). Haciendas de trapiche, hatos, hatillos y rozas: el mundo rural en la Gobernación de Santa Marta (1700-1810). Historia Caribe, 11(28), 241-274.
} 
a omitir varios rubros que gravaban no necesariamente el palo de tinte pero sí el tránsito de diminutas embarcaciones en un arco que iba de Cartagena a Maracaibo pasando por Riohacha y Santa Marta. ${ }^{8}$

El capítulo siguiente, escrito por Diana Bonnet, estudia la extracción y producción de salitre y pólvora entre 1760 y 1780 . La autora busca entender la fundación y posterior cierre de las fábricas de ambos productos en Tunja y Sogamoso. Se trata, una vez más, de un valioso aporte sobre rubros poco explorados por la literatura. Bonnet sostiene que la instauración de las fábricas obedeció a una política concreta de Estado que buscaba suplir a bajo costo productos clave para la industria militar. Su fracaso, por otra parte, obedeció a "la falta de un manejo certero en la administración de la fábrica, los costos y las distintas desavenencias entre los administradores y el personal que allí trabajaba" (p. 186). La autora proporciona una descripción interesante y necesaria de diversos aspectos de la producción salitrera. Sin embargo, como sucede con el capítulo de González, la autora no provee el contexto económico y fiscal de mediados de siglo para comprender el fenómeno a cabalidad. En términos analíticos, el texto no ofrece datos para observar el mercado de salitre y, de esta manera, señalar si el problema fue por el lado de la oferta, como sugiere la autora, o por el lado de la demanda. De hecho, la autora no ofrece datos sobre la estructura de costos que permita establecer las características de la curva de oferta y su posible carácter monopólico. Pero quizá el mayor problema del mercado de pólvora radicaba en el lado de la demanda, fenómeno que la autora no aborda. Dada la estructura de la minería aurífera neogranadina, esta no requería cantidades apreciables del producto y, por tanto, la curva de demanda era altamente inelástica si se le compara, por ejemplo, con la demanda de pólvora de la minería novohispana. Infortunadamente Bonnett no dialoga con la historiografía reciente sobre estancos y fisco en el Nuevo Reino. ${ }^{9}$

En el penúltimo capítulo Cintia Arango aborda la relación entre esclavitud, minería y poblamiento en el altiplano norte antioqueño durante el siglo XVIII. Arango señala que la construcción de rancherías y el despliegue de cuadrillas de esclavos constituían un proceso clave en proceso de expansión territorial de la región. La autora provee datos interesantes sobre la estructura de las cuadrillas y los métodos de explotación aurífera en un periodo poco explorado por la historiografía. Sin embargo, el argumento está sustentado en un andamiaje teórico y metodológico controversial. Para empezar, la autora sostiene que su estudio de caso se desenvuelve en el contexto de la crisis metalífera del siglo

\footnotetext{
${ }^{8}$ Véase E. Bassi (2012). Between Imperial Projects and National Dreams: Communication Networks, Geopolitical Imagination, and the Role of New Granada in the Configuration of a Greater Caribbean Space, 1780s-1810s (PhD Dissertation). University of California, Irvine.

${ }^{9}$ Véase balance en J. Pinto (2016). El reformismo fiscal borbónico en la Nueva Granada, balance y perspectivas. Historia Caribe, 11(29), 53-82.
} 
XVII. El argumento ha sido sostenido durante años y, en el caso neogranadino, se ha asumido sin mayor discusión académica. Es claro, sin embargo, que luego de los estudios de Michel Morineau refinados posteriormente por Ruggiero Romano, es imposible seguir hablando de una crisis minera generalizada. ${ }^{10}$ Los datos muestran un aumento de la exportación metalífera americana hacia Europa. Lo que colapsó, en realidad, fue la cantidad del tesoro canalizado por autoridades y comerciantes españoles. Es probable que existiese, para usar el sugestivo título de Romano, una contracoyuntura. En Nueva Granada si bien los quintos se desplomaron, la producción de moneda aumentó de manera sostenida durante el siglo. ${ }^{11}$ Hubiese sido difícil expandir la producción de numerario en medio de una contracción minera generalizada.

Por otra parte, la autora afirma que dado el carácter de la minería de placer esta dependía del régimen de lluvias. Sin embargo, esto también depende del grado de intensidad de capital y en la estructura del trabajo esclavo. La historiografía ha mostrado cómo los mineros desplegaban un cuidadoso cálculo de costos para mantener el flujo de ingresos a través de inversiones en capital fijo y en otorgamiento de márgenes autónomos de ingresos a los esclavos para cubrir costos variables. ${ }^{12}$ Existen otros aspectos de la metalogénesis y la geomorfología de la región que la autora no tiene en cuenta. Por ejemplo, las minas del cinturón minero antioqueño tenían un carácter polimetálico que afectaba el margen de ingresos de los mineros. En efecto, a diferencia de las minas del Litoral Pacífico, las minas antioqueñas contenían oro asociado con plata que sólo podía ser separada en la Casa de Moneda en Bogotá. Este hecho transformó no sólo el régimen monetario, sino también la estructura minera de la región. ${ }^{13}$ Se trata, de nuevo, de discusiones de la historiografía reciente no tenidas en cuenta.

Existen otras omisiones que debilitan de manera decisiva el argumento de Arango. Por ejemplo, la autora señala que la alcabala era "cobrada sobre todas las mercancías circulantes en las colonias españolas” (p. 222). Se trata de una aseveración incorrecta sustentada en el Diccionario de Autoridades. La alcabala no recaía sobre todas las mercancías, y su mecanismo y tasa de recaudo

\footnotetext{
${ }^{10}$ R. Romano (1993). Coyunturas opuestas. La crisis del siglo XVII en Europa e Hispanoamérica. México: Fondo de Cultura Económica.

${ }^{11}$ Véanse las cifras en G. Céspedes (1996). Las casas de moneda en los Reinos de Indias 15361825 v.1. Madrid: Museo de la Casa de la Moneda.

${ }^{12}$ W. Sharp (1975). Slavery on the Spanish Frontier. The Colombian Chocó 1680-1810. Norman: University of Oklahoma Press; V. Torres (2013). Minería y moneda en el Nuevo Reino de Granada. El desempeño económico en la segunda mitad del siglo XVIII (pp. 168-174). Bogotá: Instituto Colombiano de Antropología e Historia.

${ }^{13}$ Torres (2013). Minería y moneda..., pp. 131-138.
} 
variaba según la región y el periodo. De nuevo, existe una rica historiografía sobre circulación de mercancías que utiliza las alcabalas como insumo pero que los diversos autores del texto no consultaron. ${ }^{14}$

El último capítulo, escrito por Robinson Salazar, analiza el precio de los esclavos en San Gil entre 1700-1770. El autor es riguroso en describir los volúmenes y precios promedio de esclavos a lo largo del periodo. Se trata de un texto interesante porque arroja luces sobre el funcionamiento del mercado de cautivos en regiones no mineras. El autor identifica una tendencia secular a la baja del precio de los esclavos durante el periodo estudiado. Salazar ofrece una explicación tradicional a esta tendencia: "la trasformación de la población por el mestizaje y la reproducción local de cautivos que posibilitan el autoabastecimiento de brazos" (p. 254). El autor, entonces, propone una visión desde el perfil demográfico de la región. Sin embargo, como señalé atrás, un análisis de precios debe analizar los diversos componentes del mercado. Carlos Valencia, por ejemplo, ha mostrado cómo existió una relación entre trabajo libre, trabajo forzoso y nivel agregado de ingreso. ${ }^{15}$ Es decir, el precio de los esclavos debe analizarse a la luz de los ciclos económicos del virreinato y del mercado de trabajo para así entender su evolución. Un aumento de la mano de obra libre no necesariamente lleva a una reducción del precio de los cautivos pues la productividad marginal de ambas formas de trabajo no es necesariamente la misma en todos los sectores de la economía. Sectores intensivos en capital y con economías de escala, por ejemplo, pueden cubrir los gastos en esclavos incluso en regiones con abundante mano de obra libre. ${ }^{16}$

Igualmente, un aspecto técnico resaltado por Valencia -no considerado por Salazar- es importante: si se proporciona un precio promedio debe proveerse también su desviación estándar. En efecto, dado el tamaño de la muestra de transacciones de esclavos, dos promedios en apariencia distintos pueden no serlo si se somete la desviación estándar a las pruebas estadísticas correspondientes. ${ }^{17}$ Por ejemplo, Salazar afirma que el precio promedio de las mujeres

\footnotetext{
${ }^{14}$ E. Muñoz (2012). "Independencia y actividad económica. Tendencias cuantitativas en la renta de alcabalas de Santa Fe, Virreinato de la Nueva Granada, 1780-1821. En H. Bonilla (ed.), Consecuencias económicas de la independencia (pp. 17-43). Bogotá: Universidad Nacional de Colombia; E. Muñoz y J. Torres (2013). La función de Santafé en los sistemas de intercambio de la Nueva Granada a fines del siglo xviII. Fronteras de la Historia, 18(1), 172-175.

${ }^{15}$ C. Valencia (2001). La esclavitud como indicador del desempeño económico neogranadino. Fronteras de la Historia, 6, 109-121.

${ }^{16}$ Véase R. Allen et al. (2012). The Colonial Origins of Divergence in the Americas: A Labour Market Approach. Journal of Economic History, 72(4), 863-894.

${ }^{17}$ C. Valencia (2003). Alma en boca y huesos en costal. Contrastes socioeconómicos de la esclavitud. Santafé, Mariquita y Mompox. Bogotá: Instituto Colombiano de Antropología e Historia, y C. Valencia (2014). La producción de la libertad: economía de los esclavos manumitidos en Río de Janeiro a mediados del siglo XIX. Bogotá: Instituto Colombiano de Antropología e Historia.
} 
adultas fue de 231 pesos frente a los 222 pesos de los hombres adultos. A continuación, el autor ofrece hipótesis para explicar este premio sobre el precio de las mujeres. Como bien señala Valencia, si la desviación estándar es bastante alta como porcentaje del promedio, es probable que ambos promedios sean iguales. En otras palabras, es factible que el precio de esclavos hombres y mujeres haya sido el mismo. Este mismo ejercicio aplica para todas las comparaciones hechas entre los precios promedio por edades, etnias y regiones.

En conclusión, el conjunto de ensayos compilados en el texto constituye un aporte valioso en cuanto incursiona en temas poco explorados por la literatura. Sin embargo, el conocimiento sobre la historia colonial del Nuevo Reino de Granada requiere una estrecha colaboración entre diversas tradiciones historiográficas. El desconocimiento de la literatura reciente no sólo permite la reproducción acrítica de argumentos ya cuestionados, sino también la reproducción de errores que afectan la solidez de cualquier texto. Sólo el acercamiento de la historia económica y fiscal, por un lado, y la historia social y política por el otro, puede ayudar a ofrecer una imagen de un virreinato mucho más integrado a través de la circulación de información y mercancías. 